\title{
Solvent Extraction of Nickel(II) with Kelex 100 and 8-Sulfonamidoquinolines
}

\author{
-Shunsuke IDE* and Makoto TAKAGI** \\ *Department of Chemistry, Faculty of Liberal Arts, Kitakyushu College of Technology, \\ Shii, Kokuraminami, Kitakyushu 803 \\ **Department of Organic Synthesis, Faculty of Engineering, Kyushu University, \\ Hakozaki, Fukuoka 812
}

\begin{abstract}
Liquid-liquid extraction of $\mathrm{Ni}(\mathrm{II})$ ion by Kelex 100 and 8-sulfonamidoquinolines in chlorobenzene was studied at $25^{\circ} \mathrm{C}$. The extraction equilibrium was established only slowly, requiring generally $24 \mathrm{~h}$ mechanical shaking. The extractants $(\mathrm{HL})$ behaved as bidentate monoanionic chelating ligands, forming $1: 2\left(\mathrm{Ni}^{2+}: \mathrm{L}^{-}\right)$complexes on metal extraction. The overall extraction constants $\left(\log K_{\text {exi }} K_{\text {ex }}=\left[\mathrm{NiL}_{2}\right]_{\mathrm{org}}\left[\mathrm{H}^{+}\right]_{\mathrm{aq}}^{2} /\left[\mathrm{Ni}^{2+}\right]_{\mathrm{aq}}[\mathrm{HL}]_{\text {org }}^{2}\right.$ were in the order of -6 for Kelex 100 and in the range of $-8--10$ for 8-sulfonamidoquinolines depending on the nature of organic sulfonyl groups. A small synergistic effect by trioctylphosphine oxide, 4-benzylpyridine and 6-nitroquinoline as well as by Kelex 100 itself was observed in the extraction by Kelex 100.
\end{abstract}

Keywords Liquid-liquid extraction, Kelex 100, 8-sulfonamidoquinolines, nickel(II) ion, synergistic effect

Kelex 100 (7- $\mathrm{C}_{12} \mathrm{H}_{23}-8$-hydroxyquinoline) $)^{1-8}$ and LIX $34^{9}$ (or 8-sulfonamidoquinolines ${ }^{10-14}$ ) are the metal extraction reagents having somewhat analogous chemical structures to each other. They are only slightly soluble in aqueous solution, and the reagent loss in liquid-liquid metal extraction is minimal. In this respect, these reagents have a potential use in various solvent extraction-based preconcentration and separation devices in analytical chemistry.

While many metal ions have been described for the extraction by these reagents, no reports seem to have treated the extraction of $\mathrm{Ni}(\mathrm{II})$ ion. This is obviously due to the sluggishness and poor reproducibility of

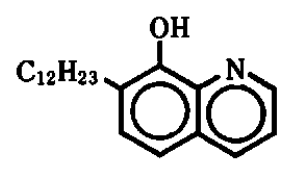

Kelex 100

$$
\begin{aligned}
& \mathrm{RSO}_{2} \mathrm{NH} \\
& \overbrace{}^{2} \\
& R=-C_{8} H_{17}\left(C_{8} A Q\right) \\
& \mathrm{R}=\mathrm{O}-\mathrm{CH}_{3}(\mathrm{PTAQ}) \\
& \mathrm{R}=\underset{\mathrm{H}_{3} \mathrm{C}}{\mathrm{H} \mathrm{C}}-\mathrm{CH}_{3}(\mathrm{MAQ})
\end{aligned}
$$

Fig. 1 Extractants: Kelex 100 and sulfonamidoquinolines.
Ni(II) extraction as our preliminary study immediately indicated. However, Ni(II) is one of the important metal ions in analytical and separation chemistry, and a complete lack of knowledge at present about its extraction behavior by these industrially-important extractants seemed rather irrational to us. Therefore, we attempted in this report to obtain the outline of $\mathrm{Ni}$ (II) extraction by Kelex 100 as well as by several 8sulfonamidoquinolines. The structures and the abbreviations of the extractants used are shown in Fig. 1.

\section{Experimental}

\section{Reagents}

Commercial Kelex 100 was distilled twice under reduced pressure $(\leq 0.1 \mathrm{~Pa})$ below $180^{\circ} \mathrm{C}$. A considerable amount of low-boiling components, including obviously 8-hydroxyquinoline, and non-volatile solid material was removed by this procedure. A slightly-brown distillate was analyzed by capillary gas chromatography-mass spectrometry. It was found that the distillate was not of a single component but contained four major groups of compounds some of which consisted of still further multiple components. Furthermore, relative abundance of the four major groups also depended on the lots of Kelex 100 obtained at different times. From mass-spectral analysis, however, it was suggested that all of these compounds included quinoidal structure (and further possibly 8hydroxyquinolinol skelton). Therefore, the distillate 
was used for extraction study without further purification.

$\mathrm{C}_{8} \mathrm{AQ}$ was prepred as described in the previous paper. ${ }^{10}$ PTAQ and MAQ were synthesized in the similar manner to that of $\mathrm{C}_{8} \mathrm{AQ}$ by using 8aminoquinoline and the corresponding arenesulfonyl chlorides.

\section{Standard Procedure}

Ten $\mathrm{cm}^{3}$ of chlorobenzene containing extractant and ten $\mathrm{cm}^{3}$ of aqueous solution containing $8.5 \times 10^{-5} \mathrm{M}(1$ $\mathrm{M}=1 \mathrm{~mol} \mathrm{dm}^{-3}$ ) nickel(II), $0.10 \mathrm{M}$ potassium nitrate (or potassium bromide) and pH-buffering agents (hydrochloric acid, Good's buffers or acetate buffer, - $0.01 \mathrm{M}$ ) were placed in 50-ml glass-stoppered centrifuge tube and equilibrated on a mechanical shaker. The organic solution contained ordinarily $1.6 \times 10^{-2} \mathrm{M}$ chelating extractant and other auxiliary reagents (trioctylphosphine oxide (TOPO), 4-benzylpyridine (4-BP) or 6-nitroquinoline (6-NQ)) where needed. The mixture was centrifuged and the $\mathrm{pH}$ of aqueous solution was measured. The metal concentration in aqueous solution was determined by atomic absorption spectrometry. The amount of metal ion extracted was calculated from the difference of the concentrations before and after extraction.

The extraction of a divalent metal ion $\left(\mathrm{M}^{2+}\right)$ from an aqueous solution by a mono-protic chelating reagent (HL) may be generally represented by the following equation:

$$
\begin{gathered}
(n+2) \mathrm{HL}_{(\mathrm{org})}+\mathrm{M}_{(\mathrm{aq})}{ }^{2}+\stackrel{\boldsymbol{K}_{\mathrm{ox}}}{\rightleftharpoons} \\
\mathrm{ML}_{2} \cdot(\mathrm{HL})_{n(\mathrm{org})}+2 \mathrm{H}_{(\mathrm{aq})}
\end{gathered}
$$

where $K_{\text {ex }}$ is an extraction constant. Subscripts org and aq indicate organic and aqueous phases, respectively. $K$ ex is defined as:

$$
K_{\mathrm{ex}}=\frac{\left[\mathrm{ML}_{2} \cdot(\mathrm{HL})_{n}\right]_{\mathrm{org}}\left[\mathrm{H}^{+}\right]_{\mathrm{aq}}^{2}}{[\mathrm{HL}]_{\mathrm{org}}^{n+2}\left[\mathrm{M}^{2+}\right]_{\mathrm{aq}}}
$$

The distribution coefficient, $D$, may be approximated under suitable conditions as:

$$
D=\frac{\left[\mathrm{ML}_{2}\right]_{\text {org }}}{\left[\mathrm{M}^{2+}\right]_{\mathrm{aq}}} \text {. }
$$

By substituing $D$ into equation (2) and by taking logarithm, equation (4) can be obtained.

$$
\log D=\log K_{\mathrm{ex}}+(n+2) \log [\mathrm{HL}]_{\text {org }}+2 \mathrm{pH} \quad \ldots \ldots
$$

Divalent metal ions were extracted by using an excess molar amount of extractants, and the metal distribution ratio was determined as a function of $\mathrm{pH}$. The plot of $\log D$ values against $\mathrm{pH}$ gave straight lines, and the slopes and intercepts were calculated by the least-squares method.

\section{Results and Discussion}

According to the above standard procedure mentioned above, nickel(II) was extracted into chlorobenzene by using $1.6 \times 10^{-2} \mathrm{M}$ extractant at various shaking time of $3,10,24$, and $48 \mathrm{~h}$. The aqueous solution contained $0.10 \mathrm{M}$ potassium nitrate and 0.01 $\mathrm{M}$ pH-buffering agent.

A large number of data points were collected at $3 \mathrm{~h}$ shaking, but as shown in Table 1 the data were considerably scattered for all the extractants studied. This is also reflected in the slopes $(\alpha)$ of linear plots, which varied in the range from 0.8 (for PTAQ) to 1.8 (for MAQ) departing from theoretical slopes of 2. A longer time of shaking seemed to reduce the problem of data scattering. Thus, at $24 \mathrm{~h}$ shaking, standard deviations were minimal, and the $\alpha$ values were 2.0 (Kelex 100), $1.7\left(\mathrm{C}_{8} \mathrm{AQ}\right.$ ), 1.8 (PTAQ), and 2.0 (MAQ). ${ }^{15} \mathrm{~A}$ further shaking for $48 \mathrm{~h}$ gave essentially the same results as those at $24 \mathrm{~h}$, suggesting that the extraction of $\mathrm{Ni}(\mathrm{II})$ took place according to reaction (1). ${ }^{16}$ Kelex 100 and MAQ seemed to reach equilibrium faster than $\mathrm{C}_{8} \mathrm{AQ}$ or PTAQ as judged from $\alpha$ and $\mathrm{pH}_{1 / 2}$ values. Especially, $\mathrm{pH}_{1 / 2}$ values of these extractants at $3 \mathrm{~h}$ shaking were virtually the same as those at equilibrium. If $\mathrm{pH}_{1 / 2}$ values at $24 \mathrm{~h}$ shaking are taken and theoretical slopes of 2 are assumed, the extraction constant defined by equation $(2)(n=1)$ can be calculated as $\left(\log K_{\mathrm{ex}}=\right)-6.4$,

\begin{tabular}{|c|c|c|c|c|c|}
\hline$n$ & $\alpha$ & $\beta$ & S.D. & $\mathrm{pH}_{1 / 2}$ & Shaking time/h \\
\hline \multicolumn{6}{|c|}{ Kelex 100} \\
\hline 12 & 1.5 & -7.4 & 0.141 & 4.9 & 3 \\
\hline 8 & 1.8 & -8.6 & 0.091 & 4.9 & 10 \\
\hline 6 & 2.0 & -9.8 & 0.007 & 5.0 & 24 \\
\hline \multicolumn{6}{|c|}{$\mathrm{C}_{8} \mathrm{AQ}$} \\
\hline 15 & 1.2 & -7.9 & 0.167 & 6.5 & 3 \\
\hline 8 & 1.5 & -9.1 & 0.135 & 6.0 & 10 \\
\hline 8 & 1.7 & -9.8 & 0.074 & 5.9 & 24 \\
\hline \multicolumn{6}{|c|}{ PTQA } \\
\hline 16 & 0.8 & -5.2 & 0.186 & 6.3 & 3 \\
\hline 6 & 1.6 & -9.0 & 0.052 & 5.8 & 10 \\
\hline 6 & 1.8 & -9.9 & 0.094 & 5.6 & 24 \\
\hline \multicolumn{6}{|c|}{ MAQ } \\
\hline 20 & 1.8 & -12.4 & 0.296 & 6.9 & 3 \\
\hline 9 & 1.8 & -12.5 & 0.069 & 6.9 & 10 \\
\hline 8 & 2.0 & -13.8 & 0.087 & 6.9 & 24 \\
\hline
\end{tabular}

Table 1 Linear relationship between $\log D$ and $\mathrm{pH}$ in the extraction of $\mathrm{Ni}(\mathrm{II})$ with $\mathrm{Kelex} 100, \mathrm{C}_{8} \mathrm{AQ}, \mathrm{PTAQ}$ and MAQ, respectively, at various shaking time $\log D=\alpha \mathrm{pH}+\beta ; 25^{\circ} \mathrm{C}$

Aqueous solution before extraction: $8.5 \times 10^{-5} \mathrm{M} \mathrm{NiCl}_{2}, 0.10 \mathrm{M}$ $\mathrm{KNO}_{3}$, Good buffer(0.01 M).

Organic solution before extraction: $1.6 \times 10^{-2} \mathrm{M}$, extractant in chlorobenzene.

Number of data points, $n$; S.D., standard deviation; $\mathrm{pH}_{1 / 2}$, half extraction $\mathrm{pH}(\log D=0)$. 
$-8.2,-7.6$, and -10.2 for Kelex $100, C_{8}$ AQ, PTAQ and MAQ, respectively. ${ }^{17}$ These values serve as a measure of $\mathrm{Ni}$ (II) extractability.

While extraction equilibrium constants are of theoretical importance, the extraction of $\mathrm{Ni}$ (II) seldom reaches its true equilibrium in ordinary laboratory procedure of metal extraction (rather short shaking time). In such instances, extraction data from $3 \mathrm{~h}$ shaking may adequately serve as a practical measure of $\mathrm{Ni}$ (II) extractability when $\mathrm{Ni}$ (II) is present and coextracted along with the metal ions of interest. From this point of view, $3 \mathrm{~h} \mathrm{Ni(II)} \mathrm{extraction} \mathrm{was} \mathrm{studied}$ under various conditions especially in the presence of anionic or neutral species which are capable of coordinating to the metal ions and thus can exert either inhibiting or promoting effect on metal extraction. The effect of "inert" salt was also studied which itself does not explicitly interact with metal ion but can affect the formation of metal chelate through variation of ionic strength of the medium. ${ }^{18-20}$ The effects of coexisting inorganic salts $\left(\mathrm{KNO}_{3}, \mathrm{KBr}\right)$ and $\mathrm{pH}$-buffering reagents (Good's buffers, acetate buffer) was studied for $\mathrm{Ni}$ (II) extraction by Kelex 100 and $\mathrm{C}_{8} \mathrm{AQ}$ under similar conditions to those of Table 1 . The results indicated no major alteration in extraction behavior. The $\alpha$ and $\mathrm{pH}_{1 / 2}$ values as well as standard deviations of linear plots were about the same as those in Table 1 . These results suggest that there are some important yet unknown chemical factors which hinder the reproducibility of $\mathrm{Ni}$ (II) extraction, apart from simply a sluggishness of $\mathrm{Ni}$ (II) chelate formation. In this regard, it is interesting to point out that the Ni(II) complex of 8-sulfonamidoquinolines can exist in either octahedral (hydrated) or square-planar configurations. ${ }^{11}$ When the complexes are isolated from aqueous solution or water-containing medium, they are hydrated and palegreenish in color. If the complex is then suspended or dissolved in acetone or other non-protic solvents, the greenish complex turns brown or red-brown (formation of square-planar complexes). The brown complexes are readily soluble in organic solvents while the green complexes are not. This transformation takes place very readily with $\mathrm{Ni}$ (II) complex of MAQ under slight warming in acetone. The similar reaction occurs with $\mathrm{Ni}(\mathrm{II})-\mathrm{C}_{8} \mathrm{AQ}$ complex, but it requires prolonged heating and higher temperature. Steric congestion in this type of ligands around the metal coordination sphere has been suggested for Ni(II)-MAQ system from the complex stability measurements. ${ }^{12}$ It is plausible that a steric repulsion exerted by 2,6 -dimethyl groups of MAQ facilitated the liberation of the two axial hydration water molecules from the octahedral $\mathrm{Ni}(\mathrm{II})$ complex of $\mathrm{MAQ}$ (Ni(II): $\mathrm{MAQ}=1: 1$ ). It is interesting to point out in this connection that in Table 1 MAQ seems to reach extraction equilibrium much faster than $\mathrm{C}_{8} \mathrm{AQ}$. It is possible that in the present solvent extraction system, $\mathrm{Ni}(\mathrm{II})-8$-sulfonamidoquinoline complexes are in equilibrium between (hydrated) octahedral and square-planar configurations, and then a limited rate of their interconversion provided an added difficulty in obtaining extraction equilibrium data within reasonable equilibration time and with reasonable reproducibility.

Table 2 summarized the effect of neutral ligands which were used as auxiliary reagent in the extraction of $\mathrm{Ni}(\mathrm{II})$. TOPO is known to form adducts with

Table 2 Liner relationship between $\log D$ and $\mathrm{pH}$ in the extraction of $\mathrm{Ni}(\mathrm{II})$ with $\mathrm{Kelex} 100$ or $\mathrm{C}_{8} \mathrm{AQ}$ containing various auxiliary reagent

$\log D=\alpha \mathrm{pH}+\beta ; 25^{\circ} \mathrm{C}$

\begin{tabular}{|c|c|c|c|c|c|c|c|}
\hline Extractant & $\begin{array}{l}\text { Auxiliary reagent } \\
\text { (conc., M) }\end{array}$ & $\begin{array}{c}\text { Inorganic salt } \\
\text { (conc., M) }\end{array}$ & $n$ & $\alpha$ & $\beta$ & S.D. & $\mathrm{pH}_{1 / 2}$ \\
\hline Kelex 100 & $\begin{array}{r}\text { TOPO }\left(1.6 \times 10^{-3}\right) \\
"\left(1.6 \times 10^{-2}\right) \\
"(0.01) \\
4-\mathrm{BP}\left(1.6 \times 10^{-3}\right) \\
"\left(1.6 \times 10^{-2}\right) \\
6-\mathrm{NQ}\left(1.6 \times 10^{-2}\right)\end{array}$ & $\begin{array}{c}\mathrm{KNO}_{3}(0.1) \\
" \quad(0.1) \\
\mathrm{KBr}(0.01) \\
\mathrm{KNO}_{3}(0.1) \\
" \quad(0.1) \\
" \quad(0.1)\end{array}$ & $\begin{array}{r}9 \\
17 \\
18 \\
17 \\
10 \\
4\end{array}$ & $\begin{array}{l}1.7 \\
1.6 \\
1.8 \\
1.5 \\
1.7 \\
2.0\end{array}$ & $\begin{array}{l}-8.2 \\
-7.5 \\
-8.1 \\
-7.4 \\
-7.2 \\
-9.3\end{array}$ & $\begin{array}{l}0.074 \\
0.191 \\
0.189 \\
0.143 \\
0.107 \\
0.046\end{array}$ & $\begin{array}{l}4.8 \\
4.7 \\
4.6 \\
4.9 \\
4.4 \\
4.7\end{array}$ \\
\hline $\mathrm{C}_{8} \mathrm{AQ}$ & $\begin{aligned} & \text { TOPO }\left(1.6 \times 10^{-3}\right) \\
& "\left(1.6 \times 10^{-2}\right) \\
& "(0.01) \\
& \prime(0.01) \\
& 4-B P\left(1.6 \times 10^{-3}\right) \\
& "\left(1.6 \times 10^{-2}\right) \\
& \text { 6-NQ }\left(1.6 \times 10^{-2}\right)\end{aligned}$ & $\begin{array}{c}\mathrm{KNO}_{3}(0.1) \\
\mathrm{KNO}_{3}(0.1) \\
" \quad(0.1) \\
\mathrm{KBr}(0.01) \\
\mathrm{KNO}_{3}(0.1) \\
" \quad(0.1) \\
" \quad(0.1)\end{array}$ & $\begin{array}{r}7 \\
11 \\
8 \\
17 \\
15 \\
12 \\
6\end{array}$ & $\begin{array}{l}1.3 \\
1.8 \\
1.3 \\
1.4 \\
1.0 \\
1.2 \\
0.9\end{array}$ & $\begin{array}{l}-7.2 \\
-9.9 \\
-6.4 \\
-7.2 \\
-5.9 \\
-6.8 \\
-5.2\end{array}$ & $\begin{array}{l}0.190 \\
0.201 \\
0.295 \\
0.217 \\
0.344 \\
0.472 \\
0.119\end{array}$ & $\begin{array}{l}5.5 \\
5.5 \\
4.9 \\
5.0 \\
5.9 \\
5.7 \\
5.7\end{array}$ \\
\hline
\end{tabular}

Aqueous solution before extraction: $8.5 \times 10^{-5} \mathrm{M} \mathrm{NiCl}_{2}$, inorganic salt, Good buffer $(0.01 \mathrm{M})$.

Organic solution before extraction: $1.6 \times 10^{-2} \mathrm{M}$ extractant, auxiliary reagent (TOPO, trioctylphosphine oxide; 4-BP, 4-benzylpyridine; 6-NQ, 6-nitroquinoline).

Three hours' equilibration at $25^{\circ} \mathrm{C}$. 
Table 3 Linear relationship between $\log D$ and $\mathrm{pH}$ in the extraction of $\mathrm{Ni}(\mathrm{II})$ with Kelex 100 in chlorobenzene at various concentrations

$\log D=\alpha \mathrm{pH}+\beta ; 25^{\circ} \mathrm{C}$

\begin{tabular}{cccccc}
\hline $\begin{array}{c}\text { Kelex 100 } \\
\text { (conc., M) }\end{array}$ & $n$ & $\alpha$ & $\beta$ & S.D. & pH $_{1 / 2}$ \\
\hline 0.02 & 10 & 1.3 & -6.5 & 0.109 & 4.8 \\
0.03 & 11 & 1.2 & -5.8 & 0.207 & 4.9 \\
0.05 & 10 & 1.6 & -6.8 & 0.099 & 4.3 \\
0.10 & 18 & 1.7 & -6.3 & 0.192 & 3.8 \\
0.30 & 10 & 1.9 & -6.8 & 0.103 & 3.6 \\
\hline
\end{tabular}

Aqueous solution before extraction: $8.5 \times 10^{-5} \mathrm{M} \mathrm{NiCl}_{2}$, Good buffer(0.01 M).

Three hours' equilibration at $25^{\circ} \mathrm{C}$.

coordinatively-unsaturated chelate complexes such as cobalt and zinc dithizonates and accelerate the rate of extraction of the metal complexes. Pyridine and its derivatives are also known to facilitate the extraction of cobalt and nickel dithizonates into carbon tetrachloride. ${ }^{21}$ Considering these, it may be expected that Kelex 100 and 8-sulfonamidoquinolines undergo similar synergistic effects by neutral ligands in the extraction of Ni(II). However, it is indicated in Table 2 that there were not observed any clear synergistic effect for TOPO, 4-BP and 6-NQ in the extraction of Ni(II) by Kelex 100 and $\mathrm{C}_{8} \mathrm{AQ}$, so far as these auxiliary reagents were used in the concentrations comparable to those of the extractants. However, a slight tendency observed for Kelex 100 should be noticed that the $\mathrm{pH}_{1 / 2}$ values were lowered as the concentration of the auxiliary reagent increased. This is an indication that TOPO, 4-BP and 6-NQ are acting as synergistic agent though the extent is rather limited. For $\mathrm{C}_{8} \mathrm{AQ}$, on the other hand, the data point scattering was dominant, precluding any detailed inspection of $\mathrm{pH}_{1 / 2}$ values.

Table 3 shows the effect of the extractant concentration on $\mathrm{Ni}$ (II) extraction by Kelex 100 . As expected, the increase in the extractant concentration lead to the lowering of $\mathrm{pH}_{1 / 2}$ values. The plots of $\mathrm{pH}_{1 / 2}$ against $-\log [\mathrm{HL}]$ org were found to give straight line of slope 1.2 though the plots considerably scattered (S.D. $=0.172$ ). The obtained slope (1.2) is appreciably higher than the theoretical slope of 1 predicted from reaction (1) or equation (4) when $n$ values in these equations are assumed to be zero. This suggests that the extraction process involving more than two molecules of Kelex 100 is partially taking part in the extraction of $\mathrm{Ni}(\mathrm{II})$. The results in Table 1 indicated that two molecules of Kelex 100 are involved as monoanionic ligands in the extraction of Ni(II). Therefore, the third molecule of the extractant should be acting as neutral synergistic agent. ${ }^{22}$ This is in accord with the observation in Table 2 that TOPO, 4-BP and 6-NQ can act as synergistic agent in the extraction with Kelex 100.
The authors wish to thank Mr. T. Yamashita and Mr. A. Kido of the Kitakyushu Municipal Institute of Environmental Health Sciences for measurements by gas chromatography-mass spectrometry.

\section{References}

1. A. W. Ashbrook, Hydrometallurgy, 1, 93 (1975).

2. A. W. Ashbrook, J. Chromatogr., 105, 151 (1975).

3. G. M. Ricety, CIM Bull., 75, April (1973).

4. G. M. Ritcey and B. H. Lucas, CIM Bull., 87, Feb. (1974).

5. G. M. Ritcey and B. H. Lucas, CIM Bull., 105, Feb (1975).

6. D. S. Flett, J. A. Hartlage, D. R. Spink and D. N. Okuhara, J. Inorg. Nucl. Chem., 37, 1967 (1975).

7. V. I. Lakshmanan and G. J. Lawson, J. Inorg. Nucl. Chem., 35, 4285 (1973).

8. G. Harrison, V. I. Lakshmanan and G. J. Lawson, Hydrometallurgy, 1, 339 (1976).

9. M. J. Virnig, Proceedings of the International Solvent Extraction Conference, 1977, p. 536 (1979).

10. M. Takagi, T. Omori, S. Mathuo, K. Ueno and S. Ide, Chem. Lett., 1980, 387.

11. S. Ide, T. Yoshida, S. Mathuno, M. Takagi and K. Ueno, Anal. Chim. Acta, 149, 235 (1983), and references cited therein.

12. H. Nakamura, T. Yoshida, M. Todoko, K. Ueno and $M$. Takagi, Bull. Chem. Soc. Jpn, 57, 2839 (1984).

13. K. Yoshizuka, K. Kondo and F. Nakashio, J. Chem. Eng. Jpn., 18, 383 (1985).

14. K. Yoshizuka, K. Kondo and F. Nakashio, J. Chem. Eng. Jpn., 18, 383 (1985).

15. The $\alpha$ values are very sensitive to the experimental errors involved in the data points at low or high metal extraction ratios (i.e., $D \leq 0.2$ or $D \geq 5$ ). Therefore, $\alpha$ values and standard deviations of the linear plots can serve as a useful measure of equilibrium attainment. On the other hand, the half extraction $\mathrm{pH}(\mathrm{pH}$ at $D=1)$ are usually not so sensitive to small errors due to unequilibration as are seen in Table 1.

16. It was at first suspected that $\alpha$ values lower than 2 indicated co-extraction of other anionic species in solution such as $\mathrm{NO}_{3}{ }^{-}$and $\mathrm{Cl}^{-}$. However, as subsequent study indicated, the use of excess $\mathrm{NO}_{3}^{-}, \mathrm{Br}^{-}$or $\mathrm{CH}_{3} \mathrm{CO}_{2}^{-}$ did not cause any alteration in the basic extraction behavior of Ni(II) ion. Therefore, it was concluded that the metal was extracted solely with proton-dissociated extractant molecule as counter anion. It was also studied about the possibility that low $\alpha$ values were caused by the formation of hydrated metal complex $\mathrm{NiL}_{2}\left(\mathrm{H}_{2} \mathrm{O}\right)_{2}$ and its dissolution in aqueous solution. However, the metal extraction generally reached $-100 \%$ in the present study, and thus such a factor could not satisfactorily explain the observed experimental facts. Theoretically, the involvement of water-soluble complex can affect the slope only slightly (moreover, it tends to increase the slope rather than decrease).

17. In this calculation, the formation of adduct complexes ( $n \geq 1$ in equation 1 ) was neglected. In fact the extent of adduct formation under the conditions of Table 1 was estimated to be rather low (see below and note 21).

18. Yu. A. Zolotov, N. M. Kuzumin, V. G. Lambrev and Tr. Komis. Po, Analit. Khim. Akad. Nauk SSSR, 15, 51 (1965). 
19 N. M. Kuzumin and Yu. A. Zolotov, Zh. Neorg. Khim., 11, 2316 (1966).

20. V. V. Bagreer and Yu. A. Zolotov, Zh. Neorg. Khim., 20, 867 (1965).

21. H. Akaiwa, H. Kawamoto and M. Hara, Nihonkagakukaishi, 90, 186 (1969).

22. Theoretical and model calculations predicted that the plots of $\mathrm{pH}_{1 / 2}$ vs. $-\log [\mathrm{HL}]_{\text {org }}$ gave a straight line with a slope between 1 and 1.5 when the number of neutral ligands within the adduct is limited to $1(n=$
1 in reaction 1). Then, a calculation further indicated that the observed slope 1.2 corresponded to the value of equilibrium constant of adduct formation, $K(K=$ $\left[\mathrm{NiL}_{2} \cdot \mathrm{HL}\right]_{\mathrm{org}} /\left(\left[\mathrm{NiL}_{2}\right]_{\text {org }}[\mathrm{HL}]_{\mathrm{org}}\right)$, of around 10 . If this value is adopted for $K$, then the extent of adduct complex formation in the organic phase under typical extraction conditions in Table 1 is in the order of $10-20 \%$.

(Received January 16, 1986) (Accepted April 16, 1986) 